\title{
Green Synthesis of Cellulosic Nanofiber in Enset Woven Fabric Structures via Enzyme Treatment and Mechanical Hammering
}

\author{
Alhayat Getu Temesgen ${ }^{1}$ (iD 0000-0001-7841-2281 \\ Recep Eren ${ }^{1,2 *}$ (D) 0000-0001-9389-0281 \\ Yakup Aykut 1,2 (D) 0000-0002-5263-1985 \\ ${ }^{1}$ Bursa Uludag University, Graduate School of Natural and Applied Sciences, Department of Textile Engineering, Bursa, Turkey \\ ${ }^{2}$ Bursa Uludag Universities, Engineering Faculty, Department of Textile Engineering, Bursa, Turkey
}

Corresponding Author: Recep Eren, erecep@uludag.edu.tr

\begin{abstract}
The rapid development of technology in textile industries has been improving textile finishing properties such as durability, water replants and breathability. Enset is effectively un-utilized agrowaste fiber composed of cellulose, hemicellulose and lignin, which are resemblance to banana fibers. This paper focused on the utilization of enset waste materials for the production of nano fiber. Enset nano fiber (ENF) was fabricated by defibrillation of raw fibers from the surface of enset woven fabrics into micro and nano-scale fibers by $\alpha$-amylase enzyme treatment and then mechanical hammering. Instead of sandwiching the nanofiber mats between conventional woven fabrics, in this research work, nanofiber mats were manufactured on the surface of the conventional woven fabrics. This top-down nanofabrication approach is simple, cost-effective and environmentally friendly nanofiber manufacturing technique from the surface of woven fabric structures. Fiber characterization was done by fourier transform infrared spectroscopy (FTIR) and scanning electron microscope (SEM). The surface area, pore size and pore volume of enset nano fiber was analyzed by brunauer, emmett and teller (BET). The test results revealed that nano fiber fabrication was significantly affected by the used enzyme concentration and applied mechanical power. Enset micro fiber was formed when $10 \%(\mathrm{w} / \mathrm{v})$ concentration of $\alpha$-amylase enzymatic treatment was applied while enset nano fibers were formed when the enzyme concentration was increased to $15 \%-20 \%(\mathrm{w} / \mathrm{v})$. The FTIR results revealed that hemicellulose and lignin were effectively removed and fine fibers were defibrillated from the crystal structure of enset woven fabrics. The SEM microscopic image also confirmed the formation of the enset nano fiber ranges from $660 \mathrm{~nm}-63 \mathrm{~nm}$.
\end{abstract}

ARTICLE HISTORY

Received: 06.07.2020

Accepted: 29.03.2021

\section{KEYWORDS}

Amylase Enzyme, Cellulose, Enset Nano Fiber, Green Synthesis, Mechanical Hammering

\section{INTRODUCTION}

Due to the rapid development of new technologies and sustainable routes, people are pushed to find out smart fabrics in addition to their comforts [1]. Nanotechnology plays a significant role in terms of increasing comfort, functionality and durability of textile products [2]. It is a mechanism used to develop next-generation materials having high surface area, flexibility, high porosity and lightweight, which are necessary for our day to day activities [3]. The properties and behavior of nano scale materials are completely different from the materials at large scale [4]. Commonly, the manufacturing of nano scale materials can be done by either bottom-up or top-down technique [5]. Recently, nanofabrication processes have been growing with new manufacturing techniques such as chemical vapor deposition, high pressure homogenization, electrospinning, chemical and biological treatment processes [6]. The fabrication approach of nanofiber must be a reliable and cost-effective process. Pressures on reducing petrochemical materials consumption and global

To cite this article: Temesgen AG, Eren R, Aykut Y. 2021. Green Synthesis of Cellulosic Nanofiber in Enset Woven Fabric Structures via Enzyme Treatment and Mechanical Hammering. Tekstil ve Konfeksiyon, 31(1), 63-. 
warming have been pushing the researchers and manufacturers to find out eco-friendly nano fibers which are obtained from natural resources [7]. Nano materials obtained from the hemicelluloses have a lot of advantages like their biodegradability and renewable natures [8].

Cellulose nanofibers are synthesized from different part of plants by different methods but their isolation processes are carried out in three steps (1) raw material pretreatments, (2) partial hydrolysis of the materials by chemical or enzyme treatments and (3) delamination of the nanofibers by mechanical mechanism such as hammering and grinding [9]. The most commonly used cellulose nanofibers synthesize techniques are done by using strong acids, called acid hydrolysis nano fiber preparation methods [9, 10]. But, this nanofiber manufacturing method has a lot of disadvantage such as toxic, non-ecofriendly and long processing steps $[10,11]$. In conventional cellulose nano fiber manufacturing methods, the utilization of cellulose materials with their effluent biochemical treatments causes significant environmental effects. For example, the dissolution of starch by either etherification or esterification processes are carried out by using huge amount of solvents. Moreover, the processes are done by involving toxic reagents. As a result successive washing is required before the cellulose nanofibers are used in different applications [12]. Recently, researchers have tried to solve this prolong steps by introducing a new environmentally friendly nanofiber manufacturing methods by using different types of enzymes [12]. The most commonly used enzymes for hydrolysis lignocellulose materials are cellulase, endoglucanases, amylase and xanthomonas [13]. Kumari P. et al. in 2019 synthesized cellulose based nanofibers from biomass of lemongrass by enzyme hydrolysis techniques. According to this study, the cellulose nano fibers were isolated by hydrolysis of the lemongrass after extracting of the oils from the leaves. This nanofiber fabrication system is not cost-effective processes. Because, this nanofiber manufacturing method needs additional chemicals such as $\mathrm{NaOH}$, solvent (acidified sodium chlorite) and buffer (sodium-citrate) for hydrolyzing lignocellulose part of lemongrass [13]. Also, Tibolla H. et al in 2014 studied the manufacturing of cellulose nanofibers from banana peel by using different chemicals and enzyme such as $\mathrm{KOH}$, $\mathrm{NaClO}_{2}, \mathrm{H}_{2} \mathrm{SO}_{4}$, xylanase and acetate as a buffer. In this nanofiber manufacturing method, the banana peel and bran were passed through alkali treatments, bleaching, acid hydrolysis and finally enzymatic treatments were carried out [14]. Similarly, Liu X. et al. in 2019 studied about cellulose nanofiber manufacturing from northern bleached softwood pulp (NBSK) by enzymatic treatments and mechanical grinning mechanisms. According to the study, the NBSK fiber was immersed in deionized water and continually grinded by Ultrafine Grinder (10-15 J with a speed of $1500 \mathrm{rpm}$ ) [15]. Qing Y. et al. in 2013 also studied about the syntheses of cellulose nanofibers from bleached Kraft eucalyptus pulp by micro-fluidization and refining processes in combination with enzyme and 2,2,6,6- tetramethylpiperidine-1-oxyl (TEMPO) oxidized treatments. The studies revealed that, the nanofiber was defibrillated by two stone grinding disks having a speed of $1500 \mathrm{rpm}$ [16]. Nanofibers obtained from cellulose based materials which are manufactured by conventional nanofabrication technologies have poorer mechanical strength [17]. In order to solve such problem, recently post-treatments and hydrogel structures have been made by crosslinking and forming network between the consecutive nanofibers [17, 18]. The manufacturing of textile products such as advanced yarns and woven fabrics from nanofibers by using commercially available yarn and fabric manufacturing machines could not easily achieve the desired textile structures [19]. Mostly nanofibers based woven fabrics are produced by sandwiching the nanofibers between two conventional woven fabric structures [19].

This research work focuses on the production of nano fibers from the surface of enset fiber woven fabrics by $\alpha$-amylase enzymatic treatment and mechanical hammering rather than sandwiching the nanofiber mats within the woven fabrics. Enset fiber is a lignocellulose fiber obtained from bast and midrib of enset plant under the Musaceae family [20]. The fibers morphologically resemble to banana fiber [21]. It is effectively un-utilized agro-waste fiber grown in Africa, especially in Ethiopia. In this study, enset nanofibers and their surface nanofiber fabrics were synthesized from the conventional enset woven fabrics by simple, cost effective and reliable physico-mechanical techniques which are not used before. $\alpha$-amylase enzyme, which is one of the most known starch digestive enzyme, was used for the removal of immature starch and hemicellulose [22]. Three different concentrations $(10 \%, 15 \%$ and $20 \% \mathrm{w} / \mathrm{v})$ of $\alpha$-amylase enzymes were used to split out lignocellulose fibers into fine fibrils with the aid of mechanical hammering until the desired level of nano fibers were obtained from enset woven fabrics [23, 24]. SEM and FTIR characterizations were used to analyze enset nano fibers. Brunauer, Emmett and Teller (BET) analyses were carried out to investigate total surface area and pore structures of enset nano fibers, which were manufactured from enset woven fabrics. The basic different of enset nanofibers fabrication techniques with $\alpha$-amylase enzyme via mechanical hammering from most commercially used nanofiber fabrication methods are, the nanofibers and their manufacturing process is organic method, high yield, no need of additional solvents and buffering agents, 2 step process, no need of grinding machine, cost effective and fully environmental friendly process.

\section{MATERIAL AND METHOD}

\subsection{Material}

The enset fabric was purchased from G7 Industrial Business Group (Addis Ababa, Ethiopia). Different concentrations of $\alpha$-amylase enzymes $(10,15$ and $20 \% \mathrm{w} / \mathrm{v})$ were used to defibrillate the immature lignocellulose part of the fibers from woven fabrics. The $\alpha$-amylase enzyme was obtained 
from chemical sells company, called "Alfa Kimya Sanayi ve Ticaret A.S". This enzyme has $1.0 \mathrm{~g} / \mathrm{cm}^{3}$ of density at room temperature, 6-7 $\mathrm{pH}$ value and it is easily soluble in water at any type of ratios. Effective working temperature of this enzyme for fabric treatment is $30-70{ }^{\circ} \mathrm{C}$.

\subsection{Method}

Enset nano fiber was produced from the surface of enset woven fabrics. Both enset fiber and enset plain woven fabrics were used for this study. For easier mechanical hammering, the enset fabric was found to be more convenient than enset fiber. In this research work, nanofibers were manufactured from the surface of the conventional enset woven fabrics. There are three major types of nano fiber fabrication approaches: mechanical, chemical and biological nano fabrication $[6,23,25]$. This study was conducted by combining the technology of biological treatments and mechanical hammering approaches for the defibrillation of fiber from the tope surface of enset woven fabrics. For this study, HP-630 hot plate and Scilogex0S40-S Mixer were used to prepare the homogenous enzyme solution and boiling the impregnated enset fabric in enzyme solutions at the desired temperature and enzyme ratios. A $2.5 \mathrm{Kg}$ weight of hammer was employed as a source of mechanical power for beating the surface of enset woven fabrics. Evo-40 Scanning Electron Microscopy (SEM) measurements were conducted for the examination of micro and nano structure of the treated and mechanically hammered enset fibers. Bruker-Tensor-37-FTIR was used for the chemical characterization of untreated and treated enset fibers. It was also used to analyse the removal of immature lignocellulose during enzymatic treatment (enzyme hydrolysis process) and mechanical hammering. BET measurement was conducted with the degassing temperature at $90{ }^{\circ} \mathrm{C}$ by using Micrometer-Tristar II, which is used to measure the specific area of nanofibers.

\section{Preparation of enset fabric samples}

Enset woven fabric samples were cut into $20 \mathrm{X} 20 \mathrm{~cm}^{2}$ dimension for homogenous enzymatic treatment and mechanical hammering.

\section{Enset nanofibers manufacturing mechanisms}

The logical approach of enset nanofiber fabrication was based on top-down nano materials manufacturing technique. Due to large numbers of inter-fibrillar hydrogen bonds present in the lignocellulose structure of enset fabrics, the defibrillation of micro- and/or nano-fibrils from the surface of enset fabrics in water is impossible only by using mechanical hammering. Also, this mechanism requires large amount of energy to defibrillate the fine fibers. In order to overcome this problem, the enset fabric was first treated with enzyme. In which the enset micro/nano fibers would be separated from each other by enzymatic treatment and mechanical hammering from the surface of woven fabrics until the desired micro and nano enset fibers were extracted, by forming a lot of branched fine fibers as depicted in Figure 1. Instead of sandwiching the nanofibers between two woven fabrics, in this work, nanofibers were manufactured on the surface of the conventional woven fabrics by continues hammering.

\section{Enzymatic treatment}

Enset fabric was treated with $\alpha$-amylase enzyme prior mechanical hammering. The prepared enset fabric samples were weighted and then pretreated with three different concentrations of $\alpha$-amylase enzyme (10, 15 and $20 \% \mathrm{w} / \mathrm{v})$ for 1 hour at a temperature of $35 \pm 2{ }^{\circ} \mathrm{C}$ with $30: 1$ material to liquid ratio. The treated enset fibers were cooled and left for 6 hours in the aqueous solution to give enough time for better swelling and digestion of hemicellulose. Hereafter, the enzyme treatments, the enset fabric samples were deactivated by raising the temperature of solution to $90{ }^{\circ} \mathrm{C}$ for 20 minutes. Then, the enset fabric was washed with hot water 3 times to remove the deactivated $\alpha$-amylase enzyme. After all these treatments, the swollen enset samples became ready for mechanical hammering.

\section{Mechanical Hammering}

The surface of enset fabrics were subjected to mechanical damage and fiber defibrillation by hammering until the desired fine fibers were defibrillated from the surface of macro scale enset woven fabric into micro/nano fibers at wet condition (wetted with diluted $\alpha$-amylase enzyme) as shown in Figure 1B. Enzymatic treatment and mechanical hammering was repeated 5 times. Then, the micro and/or nano fibers obtained by these mechanisms were boiled with water to deactivate the diluted $\alpha$-amylase enzyme at a temperature of $90{ }^{\circ} \mathrm{C}$ for 20 minutes. Finally micro and nano fibers were washed with cold water and then dried in autoclave for 30 minutes at a temperature of $110^{\circ} \mathrm{C}$ under 15 psi pressures.

\section{Enset nanofibers characterization:}

The morphology of mechanically extracted enset nano fibers from the surface of woven fabrics were examined by using SEM imaging technique. Chemical characterization of untreated enset fibers and treated enset nanofibers were analyzed by FTIR spectroscopy. The thermal decomposition properties of enset fiber and their fine fibers were examined with the help of TGA. BET analysis was done to reveal the surface area, pore size and pore volume of ENF.

\section{Mechanical strength test:}

Tensile strength of neat and mechanically hammered (treated with $\alpha$ - amylase enzyme) enset fabrics were done by using Shimadzu strength tester (with $5 \mathrm{KN}$ load cell with a speed of $100 \mathrm{~mm} / \mathrm{min}$ ). All the test specimen preparations and tests were conducted based on the ASTM standards and in warp direction. The average values were used as the measured value. 


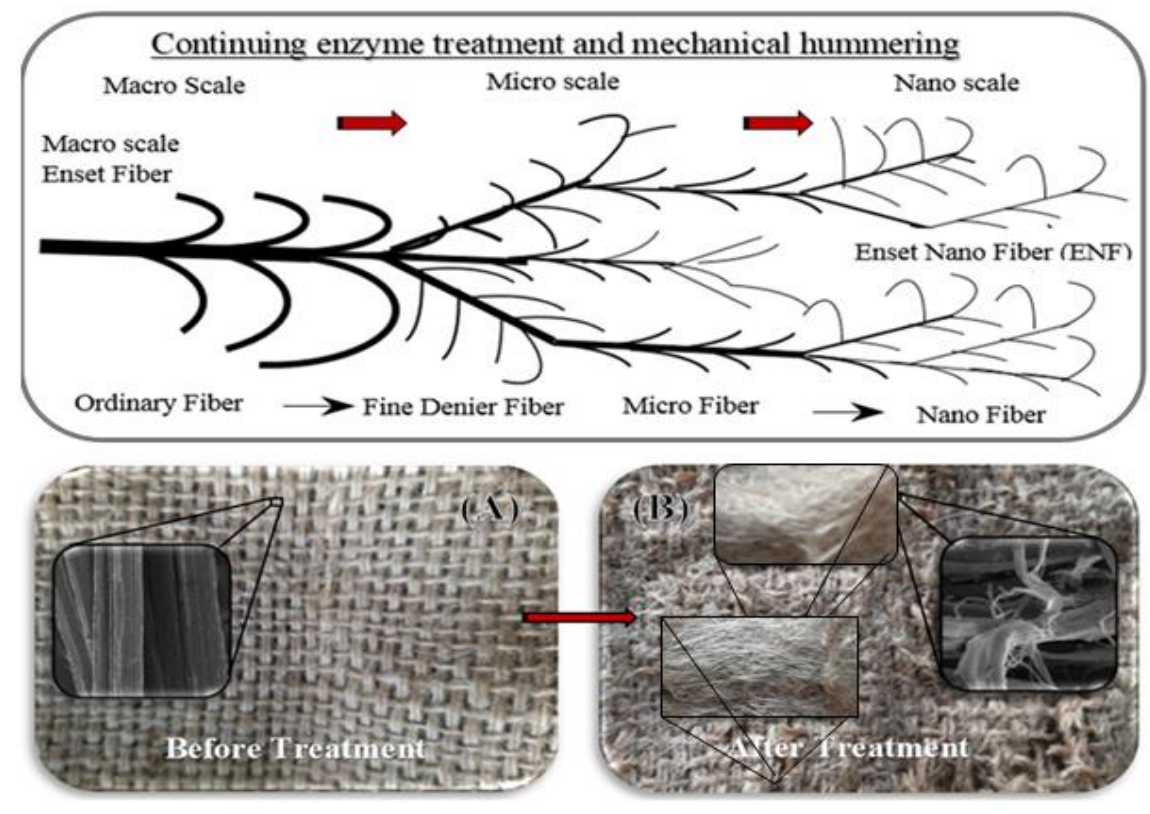

Figure 1. Schematic illustration of micro and nano enset fiber preparation by mechanical hammering.

\section{RESULTS AND DISCUSSION}

The properties and performance of textile fibers have a significant effect on the physical and mechanical behaviors of yarns as well as fabrics. Advanced fiber modification and their physico-mechanical treatment must be taken in to account on its final end use and environmental effects.
Enset nano fibers would be used to produce more advanced yarns, fabrics and composite structures having unique properties such as high durability, higher weight to strength ratio, large surface area and bio-degradable products. In this regard, morphological observations of untreated and treated enset fibers were carried out via SEM analysis.
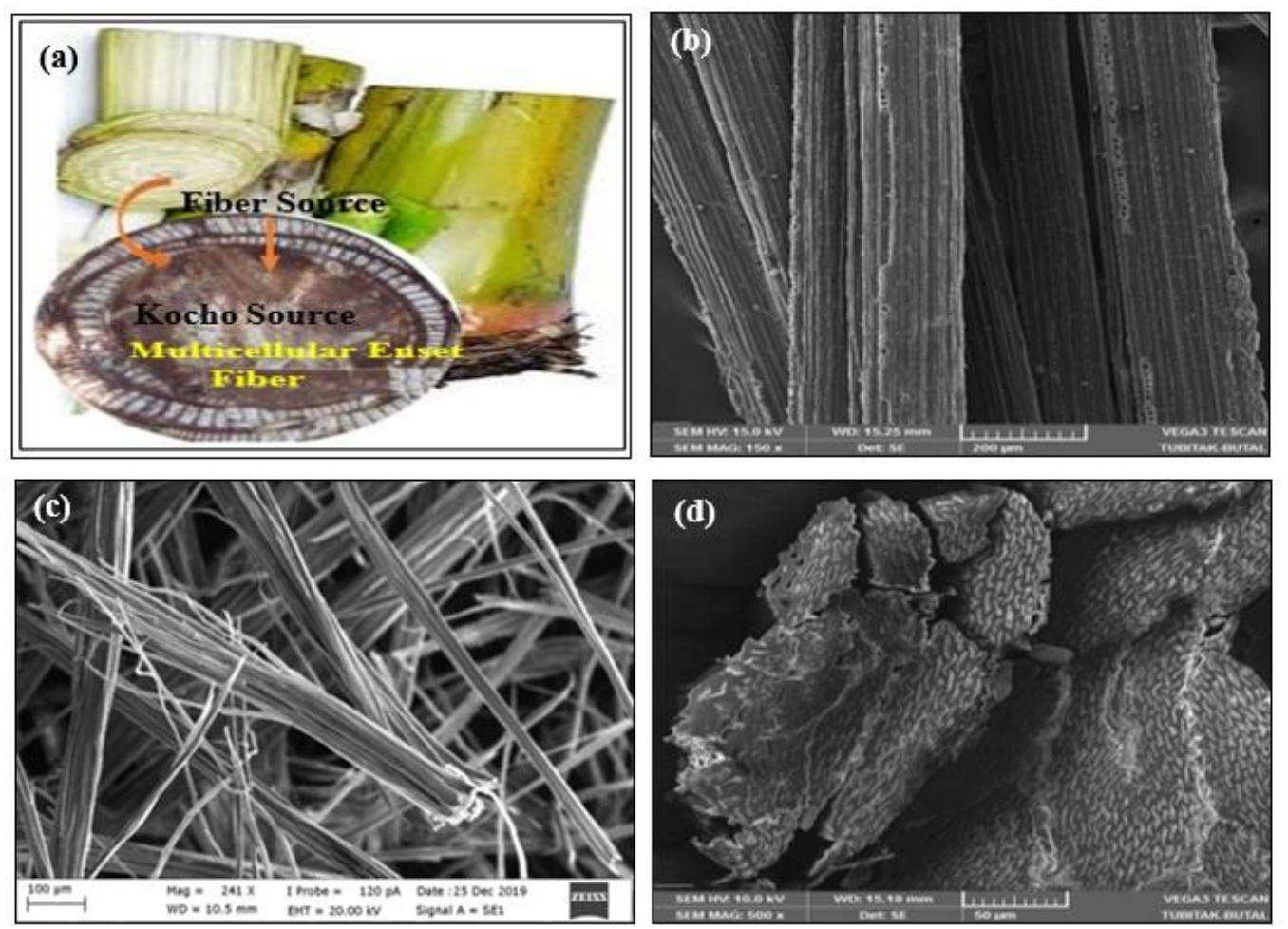

Figure 2. (a) Hallow Morphologic View of Enset Plant, Cell Phone Photograph (25Mp), (B) SEM: Natural Composite Structure of Single Enset Fiber (C) SEM: Multicellular (Bundles) View of Enset Fiber (D) SEM: Micro Pores and Cross Sectional View of Enset Fiber. 


\subsection{ENF Formation and Scanning Electron Microscope Analysis of Enset Fiber}

The microscopic images of enset fiber indicated that the fibers were defibrillated from the multicellular structures into fine fibrils having lots of helical-hollow shaped and convoluted cross sectional areas as shown in Figure 2a to Figure $2 d$. Moreover, Figure $2 \mathrm{~b}$ and $2 \mathrm{~d}$ show single macroscale enset fibers containing a number of consecutive layers in its structure. Because of its microspore structure as shown in Figure 2a and Figure 2d, the defibrillation of the fiber into micro and nano scale structures was achieved by simple mechanical hammering. The fine fiber formation occurred by the reduction of its hierarchical structure of hemicellulose and lignin parts of raw enset fibers. The defibrillation of enset fiber from the upper surface of the woven fabric created lots of branched fine fibers as shown in Figure 2c. So, enzymatic treatment and mechanical hammering was used for the separation of layered structures into a number of branched fibrils and formed new fine fibers having the same properties like the virgin enset fiber as shown in Figure 2c.

The applied treatment changed the morphology of enset fiber in terms of its size (diameter) from $2 \mu \mathrm{m}$ to $63 \mathrm{~nm}$. Figure $3 \mathrm{a}$ indicated that the enset fiber was clustered because of ineffective removal of lignin which joined cellulose and hemicellulose to form the macroscale enset fiber while Figure $3 \mathrm{~b}$ indicated that the lignin was effectively removed and naturally connected layers were started to defibrillate into two and more. Successive enzymatic treatment and mechanical hammering continued the defibrillation of enset fiber structure until the desired nano fibers were obtained (Figure $3 \mathrm{c}$ and $3 \mathrm{~d}$ ).

In a preliminary study, up to $5 \%(\mathrm{w} / \mathrm{v})$ concentration of $\alpha$ amylase enzymatic treatment, the enset fiber fibrillation was not clearly observed as seen in Figure 4 and 5 [2]. When the concentration of $\alpha$-amylase was increased up to $10 \%$ (w/v), micro fibrils having a size of 2 to $20 \mu \mathrm{m}$ were formed and additionally started to protrude from the upper surfaced of enset woven fabric (sequentially shown in points 1, 2 and 3 in Figure 4). Likewise when the concentration of $\alpha$-amylase enzyme was increased from 10 $\%(\mathrm{w} / \mathrm{v})$ to $15-20 \%(\mathrm{w} / \mathrm{v})$, macroscale fiber was further defibrillated and fine sized enset nano fibers were started to be formed depending on the applied mechanical power. At $15 \%(\mathrm{w} / \mathrm{v})$ concentration of $\alpha$-amylase enzyme, the nano fibers were observed at a large size of diameter of $133 \mathrm{~nm}-$ $660 \mathrm{~nm}$. This can be seen at point 4 in Figure 4. When the concentration of $\alpha$-amylase enzyme was increased to $20 \%$ $(w / v)$, the fibers were additionally further fibrillated into very fine scaled nano fibers having diameter between 85.07 - $63.19 \mathrm{~nm}$ shown at point 5 in Figure 4.
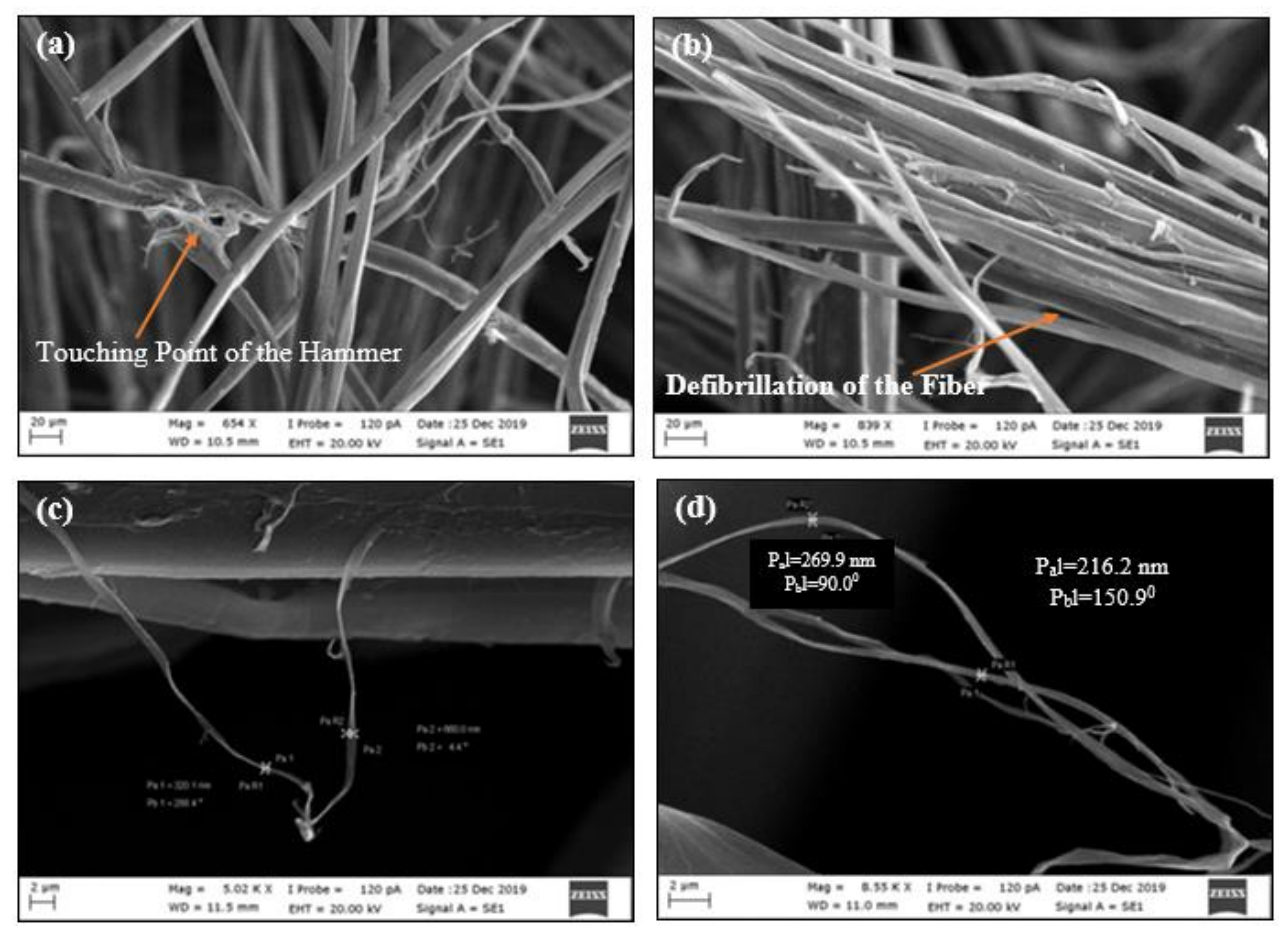

Figure 3. SEM View of $\alpha$-Amylase Enzyme Treated and Mechanical Hammered Enset Fiber: (A) Clustered Enset Fiber (B) 10\% (W/V) $\alpha$-Amylase Enzyme Concentration. (Micro Enset Fiber) (C) 15\% (W/V) $\alpha$-Amylase Enzyme Concentration (Nano Enset Fiber) (D) $20 \%$ (W/V) $\alpha$-Amylase Enzyme Concentration (Nano Enset Fiber). 


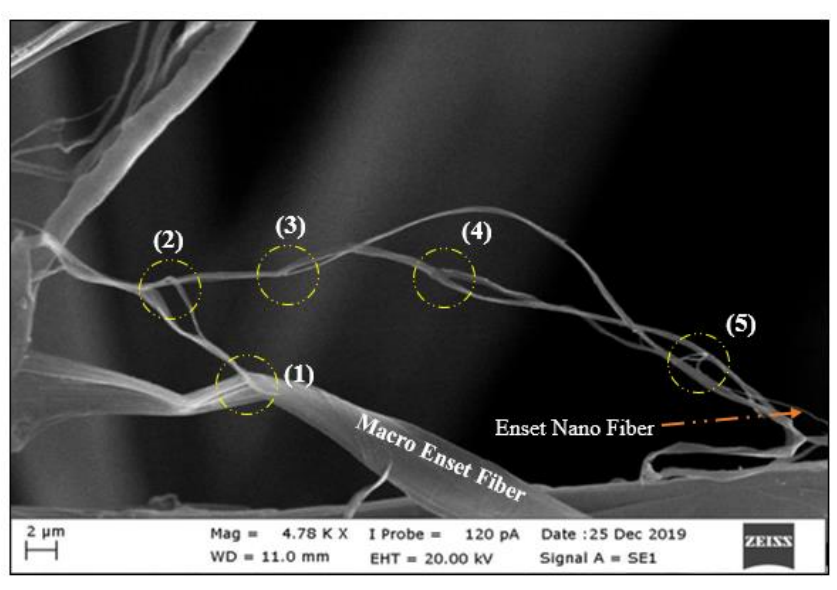

Figure 4. SEM: Hierarchical Defibrillation of Macro-Scale Enset Fiber into Enset Nano Fiber (1) Ordinarily Enset Fiber (2) Fine Denier (3) Micro Scale (4) Enset Nano Fiber Having Higher Nanometer Values and (5) Enset Nano Fiber Having Lower Nano Number Values.

The hierarchical structure of enset fibers was further defibrillated by $\alpha$-amylase enzyme and mechanical hammering was continued until lower size diameter of micro and nano fibrils were obtained. Observations made in Figure 4 and Figure 5 indicate that the virgin enset fiber was swollen and immature hemicellulose structure began to split out from the macro scale structure and form sub macro and micro structures of enset fiber. The removal of deposited film was done by mechanical hammering till the desired fine fiber structure was obtained (Figure 4).

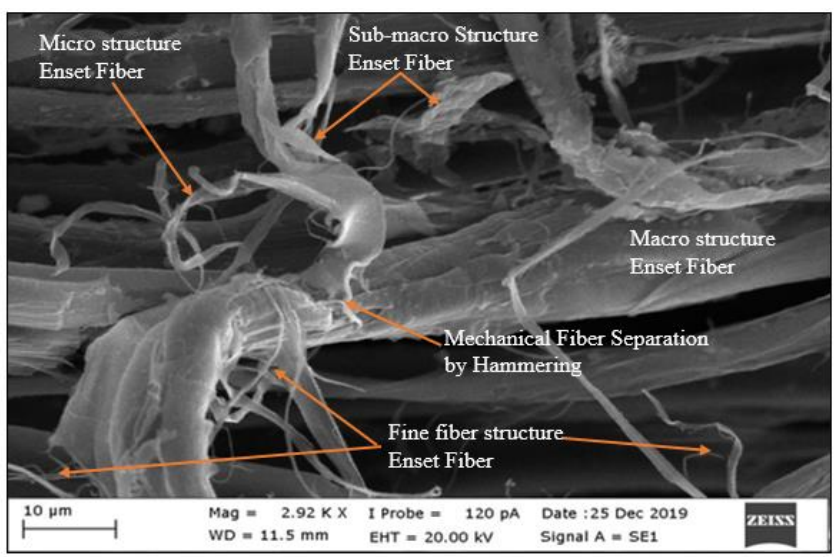

Figure 5. Gradually Removal of Hemicellulose and Lignin from the Macro Structure of Enset Fiber by Mechanical Hammering.

\subsection{Chemical Analysis of the Neat and Treated Enset Fibers with FTIR Spectroscopy}

The FTIR results were used to prove the chemical modification and defibrillation of enset fiber treated with $\alpha$ amylase enzyme. The FTIR plots of treated samples were compared with those of untreated enset fiber and given in Figure 6. The peaks in the band of FTIR spectrum of 3331 $\mathrm{cm}^{-1}$ revealed that enset fiber had O-H group in its structure [27]. With the peak at $2917 \mathrm{~cm}^{-1}$ wavelength, C-H aliphatic and aromatic stretching groups were shown and this indicates the presence of cellulose, hemicellulose and lignin $[21,27,28]$. Likewise, the peaks at $1730 \mathrm{~cm}^{-1}$ and $1665 \mathrm{~cm}^{-1}$ of enset fiber indicated the presences of $\mathrm{C}=\mathrm{O}$ stretching group of hemicellulose and $\mathrm{C}=\mathrm{O}$ stretching conjugate aromatic ring respectively [21,29]. The absorption bands between $1500 \mathrm{~cm}^{-1}$ and $600 \mathrm{~cm}^{-1}$ indicated the fingerprint region of the fiber in its infrared spectrum. The peaks at $1422 \mathrm{~cm}^{-1}$ revealed aromatic ring vibrating in cellulose and hemicellulose [30]. The absorption spectra at the peak of $1242 \mathrm{~cm}^{-1}$ and $1100 \mathrm{~cm}^{1}$ exhibited $\mathrm{C}=\mathrm{C}$ and $\mathrm{C}-\mathrm{O}$ stretching ester group of hemicellulose and lignin groups in cellulose structure respectively [31]. Moreover, the absorption at $1028 \mathrm{~cm}^{-1}, \mathrm{C}-\mathrm{O}, \mathrm{C}=\mathrm{O}, \mathrm{C}-\mathrm{C}-\mathrm{O}$ stetching were due to the presence of cellulose, hemicellulose and lignin in the enset fiber $[8,30,31]$. Curves in A and B regions in Figure 6 described a major difference in peak heights and shapes between untreated and treated enset fibers at a wave number range from 1500 to $1000 \mathrm{~cm}^{-1}$. The immature hemicellulose and excess lignin part of enset fibers began to defibrillate from the virgin enset fiber structure. Under the FTIR absorption band ranging from $1500 \mathrm{~cm}^{-1}$ to $1000 \mathrm{~cm}^{-1}$ wave number, the prominent peaks seen in Figure 6 at the point (a), (b) and (c) disappeared for the treated fibers. Moreover, the major peak shapes as well as their peak height were gradually wiped out for the treated enset fiber depending on the amount of used $\alpha$-amylase enzyme. At the wave length of $1500 \mathrm{~cm}^{-1}$, the shape of the FTIR peaks encircled with red color (A) pointed at "a", "b" and "c" in Figure 6 revealed the removal of hemicellulose from macro structure of enset fibers and the enset fibers began to defibrillate to produce micro and nano enset fibers [27,31].

The fine fibers began to defibrillate from the cellulose part of the fiber at the concentration of $10 \%(\mathrm{w} / \mathrm{v}) \alpha$-amylase enzyme as shown at point (a), encircled with black, in Figure 6. Mostly the fine fibers were obtained by this concentration up to $2 \mu \mathrm{m}$ diameter size. The peak of wave length of $1100 \mathrm{~cm}^{-1}$, corresponding to $\mathrm{C}-\mathrm{O}$ stretching conjugate (lignin) and $1321 \mathrm{~cm}^{-1}$, ring condensed stretching (lignin) revealed the removal of excess lignin from enset fibers [32]. Moreover, there was a clear peak shape difference between untreated and treated enset fiber at wave number of $1100 \mathrm{~cm}^{1}$. This phenomenon proved that the treatment of enset fiber with enzyme helped for easy defibrillation of macro fiber from woven fabrics into fine structure (encircled with black color (B) in Figure 6) [33]. At the concentration of 15 and $20 \%(\mathrm{w} / \mathrm{v})$ of $\alpha$-amylase enzyme (shown at point (b) and (c) encircled with black in Figure 6), the micro fibers were fabricated up to $2-200 \mu \mathrm{m}$ and enset nano fibers with $63-85 \mathrm{~nm}$ size respectively. 


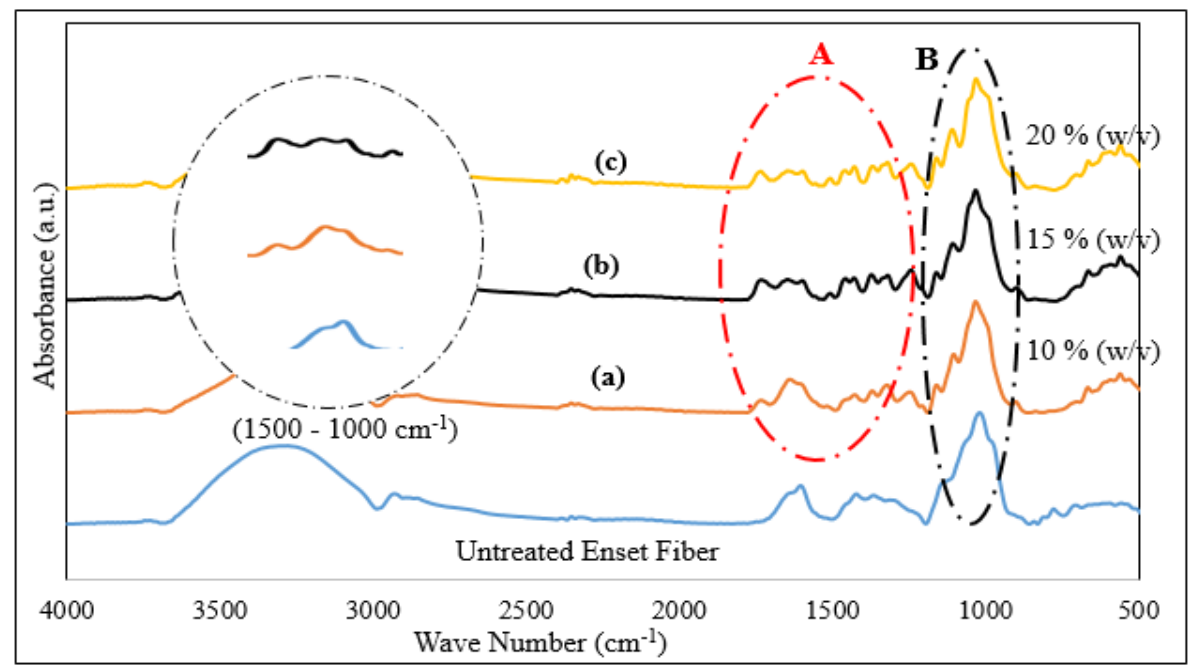

Figure 6. FTIR: Gradual Wiped-out of Hemicellulose and Lignin from Enset Fiber with $\alpha$-Amylase Enzyme Treatment and Mechanical Hammering.(a) $10 \%$ (w/v) $\alpha$-amylase Enzyme Treated,(b) 15\% (w/v) $\alpha$-amylase Enzyme Treated and (c) $20 \%$ (w/v) $\alpha$ amylase Enzyme Treated Enset Fiber.

\subsection{Thermal Characterization of Enset Nano Fiber (TGA)}

The weight loss of enset fiber and enset fine fibers were measured and analyzed by Thermo Gravimetric Analysis (TGA) with respect to the decomposition temperature. The thermal analysis was conducted between 30 and $800^{\circ} \mathrm{C}$ shown in Figure 7. The TGA curve revealed that enset fiber remained thermally stable up to the decomposition temperature reaching to $227^{\circ} \mathrm{C}$ while this temperature raised to $264^{\circ} \mathrm{C}$ with medium and highly treated enset fibers. At lower decomposition temperature ranging from $38-115^{\circ} \mathrm{C}$ of raw enset and treated fine enset fibers, only the moisture present on their components were evaporated [34]. The water loss of raw fiber and medium (15\% w/v) and highly $(20 \% \mathrm{w} / \mathrm{v})$ treated enset fibers was realized around $9 \%$ at the initial decomposition temperature of the fibers due to evaporation of water shown in Table 1. The major thermal degradation of raw, medium and highly treated enset fibers was observed at temperatures of 240 and $285{ }^{\circ} \mathrm{C}$ respectively.

A drastical thermal degradation occurred due to the breaking of glycoside linkage of cellulose, rupture of lignin and decomposition of hemicellulose [35]. The major thermal degradation of raw enset fiber was observed between 230 and $346{ }^{\circ} \mathrm{C}$ with a mass loss of $74 \%$. Whereas medium and highly treated enset fibers had a weight loss of 76 and $89 \%$ at temperature rannge of $260-390{ }^{\circ} \mathrm{C}$ respectively. The overall residuals of raw fiber, medium and highly treated enset fibers after the whole thermal decomposition were ensued 24,17 and $13 \%$ respectively at the temperature of $800{ }^{\circ} \mathrm{C}$. The TGA graph approved that medium and highly treated enset fibers have better thermal stability than raw virgin enset fibers.

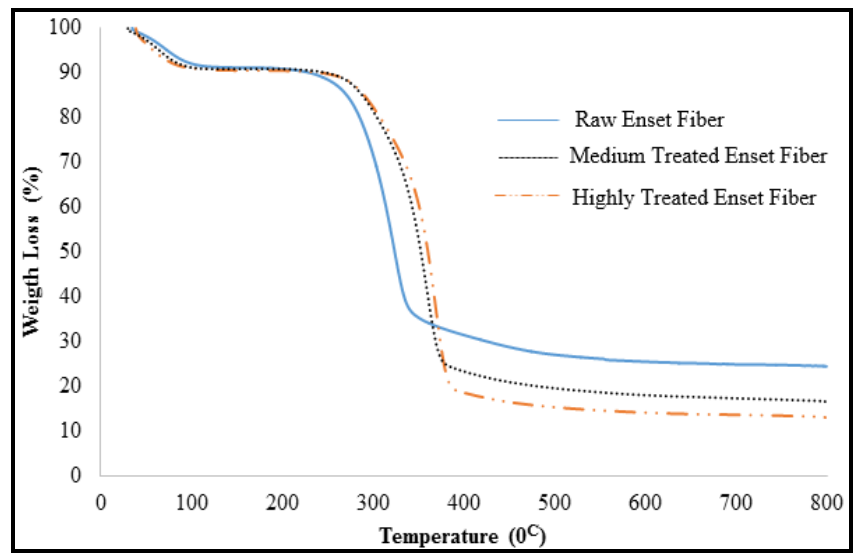

Figure 7. TGA Curves of Raw, Medium (15\% w/v) and Highly $(20 \%$ w/v. $)$ Treated Enset Fibers.

Table 1. Cumulative Weight Loss (\%) of Raw Enset Fiber and Treated Fine Fibers

\begin{tabular}{l|c|c|c|c|c|c|c|c}
\hline Type of Fiber and weight loss (\%) & \multicolumn{10}{c}{ Temperature $\left({ }^{\circ} \mathrm{C}\right)$} \\
\cline { 2 - 10 } & 100 & 200 & 300 & 400 & 500 & 600 & 700 & 800 \\
\hline Raw Enset Fiber & 9 & 10 & 30 & 70 & 73 & 75 & 75 & 75 \\
Medium Treated Enset Fiber & 9 & 10 & 20 & 78 & 81 & 82 & 83 & 83 \\
Highly Treated Enset Fiber & 9 & 10 & 20 & 82 & 85 & 86 & 87 & 87 \\
\hline
\end{tabular}


Enzymatic treatment and mechanical hammering of enset fibers resulted weight loss and fiber damage due to the hydrolysis and uncontrolled fiber breakage respectively. The concentration of enzyme and applied mechanical hammering power had a direct effect on the possibility of micro/nano fiber formation and fiber weight loss. The test result proved that, when the concentration of $\alpha$-amylase enzymes were used beyond $20 \%(\mathrm{w} / \mathrm{v})$, the enset fibers were degraded the main cellulose components of the fibers were partially destroyed rather than fine fiber formation. So in order to solve such kind of problems and to get a better quality of fine enset fiber, the applied mechanical power and concentration of enzyme must be determined in an optimum manner.

\subsection{Surface Analysis (BET) of Enzyme Treated and Mechanically Hammered Enset Fibers}

The specific surface area of the amylase treated and mechanically hammered enset fibers were investigated using nitrogen gas adsorption method and Figure 8a, 8b and 8c demonstrated the isotherms of the treated enset fibers. A typeIV isotherm and H3-type hysteresis loop was observed from the plot, and the results revealed that the fibers contained mesoporous structure $[26,36]$. The sharp rise in the loading at the lower values of $\mathrm{P} / \mathrm{Po}$ of treated enset fibers indicates a high surface area, the abrupt loading transition in the $\mathrm{P} / \mathrm{Po}$ range of $0.1-0.4$ reveals a uni-modal pore size and the presence of hysteresis confirmed that the existence of micro and mesoporous since unrestricted monolayer-multilayer adsorption occurring at high $\mathrm{P} / \mathrm{Po}$. The measured BET surface areas were $4.271,4.596$ and $11.60 \mathrm{~m}^{2} / \mathrm{gr}$ for 10,15 and $20 \%$ $w / v$ concentration of $\alpha$-amylase enzyme treated samples respectively. The surface area of treated fine enset fiber was improved by $270 \%$ when the concentration of used $\alpha$ amylase enzyme was changed from 10 to $20 \%(\mathrm{w} / \mathrm{v})$ respectively. The surface area could be increased with transforming more macro fiber to micro and nanofibers by increasing mechanical hammering and concentration of $\alpha$ amylase enzyme used.

\subsection{Mechanical Test Results of Neat and Hammered Enset Fabrics}

The mechanical strength of the fabric was purposely affected by enzyme treatment and mechanical hammering to defibrillate the micro and/or nano fibers from the surface of the fabrics. The mechanical strength of the neat and hammered (treated with enzyme) enset fabrics was investigated by using tensile and tear strength measuremets. The test results revealed that the average tensile strengths of the neat and mechanically hammered enset fabrics were 580 and $148 \mathrm{~N}$ respectively as shown in Figure 9. It indicates that the tensile strength of enzymatically treated and mechanically hammered enset fabrics were 4 times inferior to neat fabrics (loss their tensile strength by $400 \%$ ). Likewise the tear strength test results approved that the fabric tear strength was highly affected and the warp and weft threads were pulled out from the woven fabric structure rather than propagating and continue tearing processes. Because the warps and wefts threads are purposely distracted by mechanical hammering, they lost their strength as compared with neat fabrics.
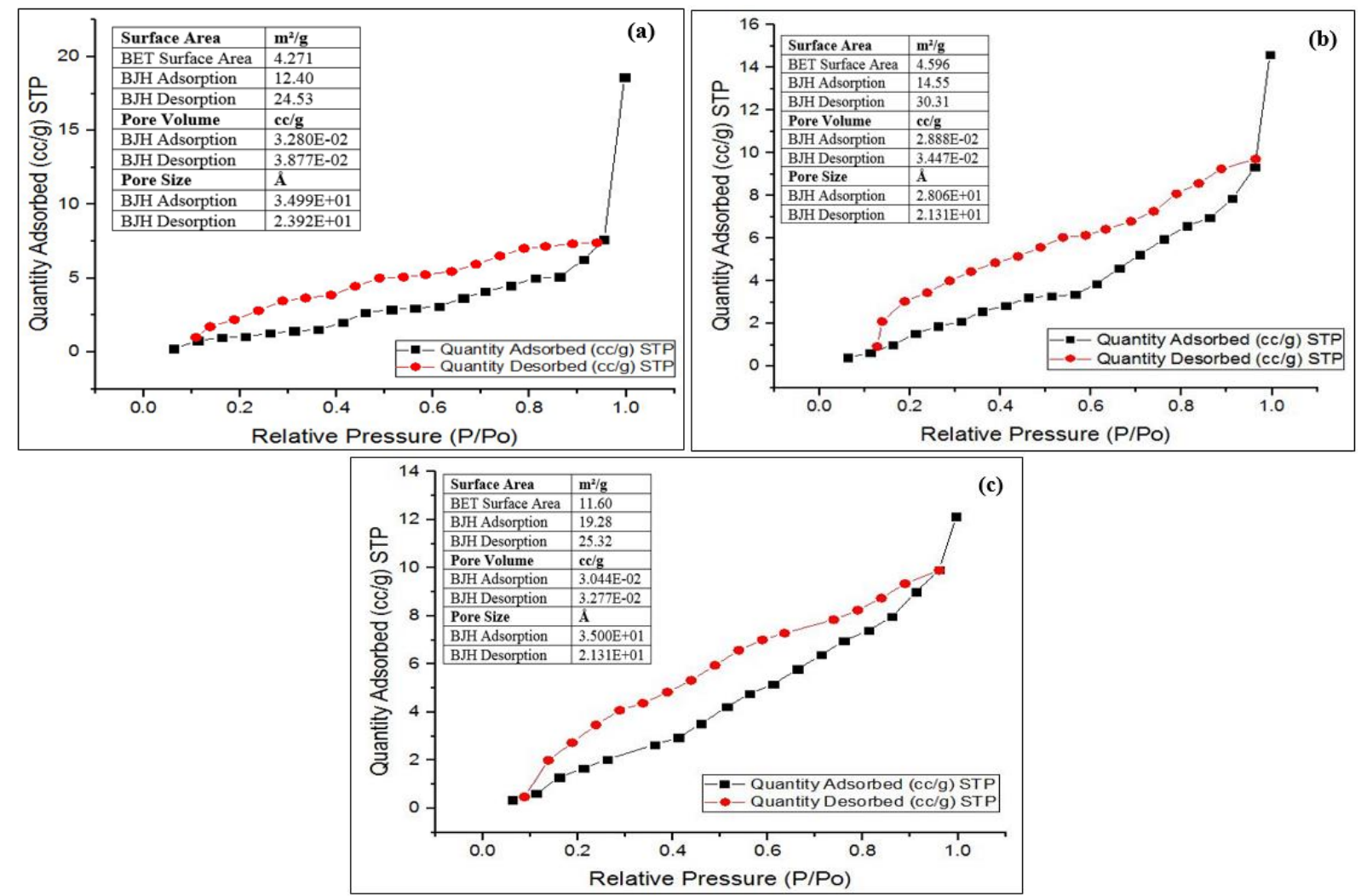

Figure 8. BET Curve, Surface Area Analysis of Treated Enset Fiber (a) $10 \%$ w/v, (b) $15 \%$ w/v and (c) $20 \%$ w/v concentration of $\alpha$ amylase enzyme. 


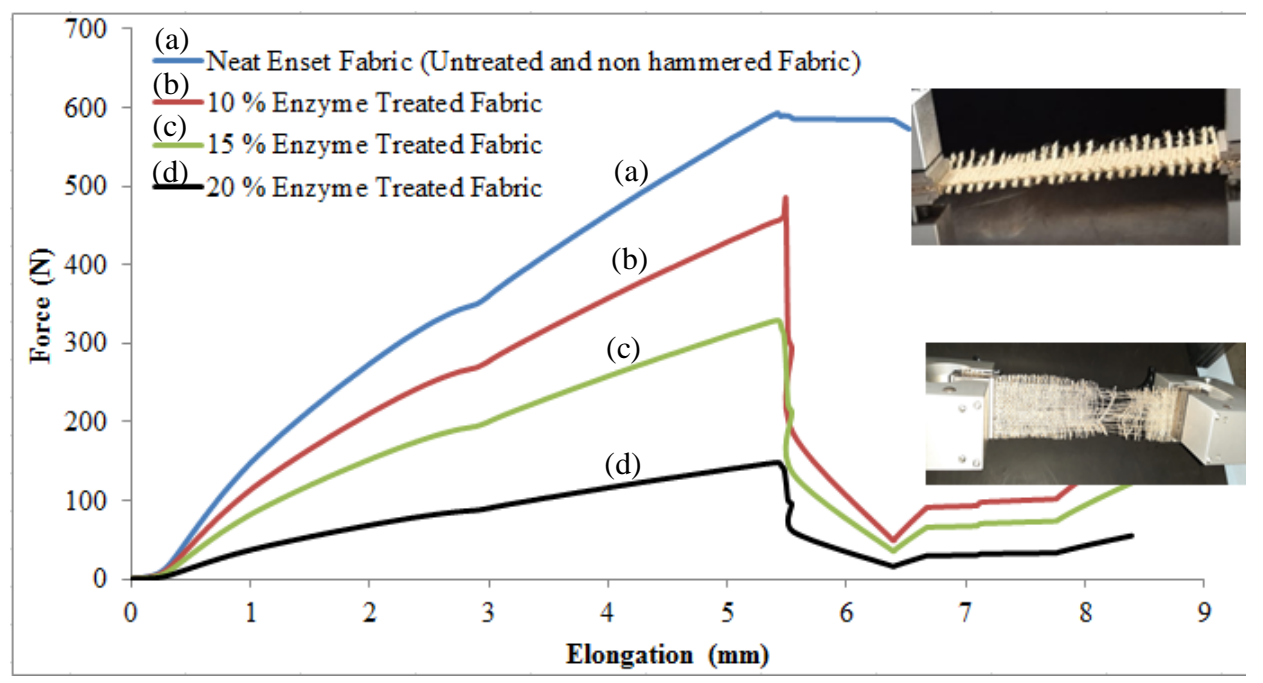

Figure 9. Neat and Mechanically Hammered (treated with $\alpha$-amylase enzyme) Enset Fabric Tensile Strength Test Results.

\section{CONCLUSION}

This research work focuses on the production of nano fibers from the surface of enset woven fabrics by $\alpha$-amylase enzymatic treatment and mechanical hammering rather than sandwiching the nanofiber mats within the woven fabrics. Enset nanofibers and their mats were synthesized on the conventional enset woven fabrics. For this purpose, enzymatic treatment and following mechanical hammering was used to remove excess immature hemicellulose and lignin from enset fibers. $\alpha$-amylase enzymatic treatment and mechanical hammering of enset fibers on the enset woven fabrics defibrillated and formed micro and nano fibers. This mechanical hammering nano fiber fabrication was a simple, cost-effective and green synthesis mechanism of fine fiber (Top-Down nanomanufacturing techniques). The formation of micro as well as nano fiber was dependent on the percentage of $\alpha$-amylase enzyme and the applied mechanical power. Higher enzyme concentration (15\% - 20 $\% \mathrm{w} / \mathrm{v}$ ) would have been a higher possibility to form nano fibers. The microscopic view revealed that green fabricated micro and enset nano fibers had a diameter of $133-660 \mathrm{~nm}$ and $63-85 \mathrm{~nm}$ respectively. The TGA graph approved that medium and highly treated enset fibers had a better thermal stability than raw enset fibers. The measured BET surface areas increased from $4.271 \mathrm{~m}^{2} / \mathrm{gr}$ to 4.596 and $11.60 \mathrm{~m}^{2} / \mathrm{gr}$ from $10 \%$ to 15 and $20 \% \mathrm{w} / \mathrm{v}$ concentration increase of $\alpha$ amylase enzyme treated samples respectively.The surface area could be increased with transforming more macro fiber into micro and nanofibers by increasing mechanical hammering time. The enset nanofiber manufactured by this study was limited on a diameter of $63 \mathrm{~nm}$ but the fabrication of very fine nanofibers having a diameter of less than $63 \mathrm{~nm}$ might be possible by using advanced mechanical hammering technologies. Textile structures produced from these enset nano fibers might have promising applications in wound healing, filtration, bionano composite manufacturing and sound absorption. A further research aiming at developing a larger scale enset micro and nanofiber production would open new areas for the use of enset fibers or fabrics which are now mostly agro-waste. The research on this aspect is in progress.

\section{Acknowledgement}

This research work was a part of Alhayat Getu TEMESGEN's PhD Thesis doing in Bursa Uludag University, Graduate School of Natural and Applied Sciences, Department of Textile Engineering. The authors gratefully acknowledge and express our sincere thanks Ömer Firat TURŞUCULAR and Abdulkarim Yahya AWOL supporting in laboratory during the study and also, Wollo University, Alfa Kimya Sanayi ve Ticaret A.S. and Mehmet TIRITTOĞLU for his supporting and allowing to use all the necessary laboratory equipment's for this study.

Conflicts of Interest: The Authors declare no conflict of interest.

\section{REFERENCES}

1. Chen G., Li Y., Bick M. and Chen J. 2020. Smart textiles for electricity generation, Chem. Rev.120(8), 3668-3720.

2. Rather L.J., Zhou Q., Ganie S.A. and Li Q. 2020. Environmental Profile of Nano-finished Textile Materials: Implications on Public Health, Risk Assessment, and Public Perception. Advances in Functional Finishing of Textiles, Springer, Singapore, 57-83.

3. Khan I., Saeed K. and Khan I. 2019. Nanoparticles: Properties, applications and toxicities. Arab. J. Chem.12(7), 908-931.
4. Chen L., Liu J., Jiang C., Zhao K., Chen H., Shi X., Chen L., Sun C., Zhang S., Wang Y. and Zhang Z. 2019. Nanoscale Behavior and Manipulation of the Phase Transition in Single-Crystal Cu2Se. Adv. Mater. 31(4), 1804919.

5. Fan P., Zhong M., Bai B., Jin G. and Zhang H. 2016. Large scale and cost effective generation of 3D self-supporting oxide nanowire architectures by a top-down and bottom-up combined approach. $R S C$ Adv., 6(51), 45923-45930. 
6. Kargarzadeh H., Mariano M., Gopakumar D., Ahmad I., Thomas S., Dufresne A., Huang J. and Lin N. 2018. Advances in cellulose nanomaterials. Cellulose 25(4), 2151-2189.

7. Jiang J., Qin N. and Tao T.H. 2020. Nanomanufacturing of biopolymers using electron and ion beams. J. Micromechanics Microengineering 30(3), 033001.

8. Lazić B.D., Pejić B.M., Kramar A.D., Vukčević M.M., Mihajlovski K.R., Rusmirović J.D. and Kostić M.M. 2018. Influence of hemicelluloses and lignin content on structure and sorption properties of flax fibers (Linum usitatissimum L.). Cellulose 25(1), 697-709.

9. Sun X. 2004. Isolation and characterisation of cellulose obtained by a two-stage treatment with organosolv and cyanamide activated hydrogen peroxide from wheat straw. Carbohydr. Polym. 55, 379391.

10. Mandal A and Chakrabarty D. 2011. Isolation of nanocellulose from waste sugarcane bagasse (SCB) and its characterization. Carbohydr Polym. 86, 1291-1299.

11. Leite ALMP, Zanon CD, Menegalli FC. 2017. Isolation and characterization of cellulose nanofibers from cassava root bagasse and peelings. Carbohydr Polym.157,962-970.

12. Isogai A. and Bergström L. 2018. Preparation of cellulose nanofibers using green and sustainable chemistry. Curr. Opin. Green Sustain. Chem.12, 15-21.

13. Kumari P., Pathak G, Gupta R., Sharma D. and Meena A. 2019. Cellulose nanofibers from lignocellulosic biomass of lemongrass using enzymatic hydrolysis: characterization and cytotoxicity assessment. J. Pharm. Sci. 27, 683-693.

14. Tibolla H., Maria F., Florencia P. and Menegallia C. 2014. Cellulose nanofibers produced from banana peel by chemical and enzymatic treatment. Int. J. Food Sci. Technol. 59(2), 1311-1318.

15. Liu X. Jiang Y., Song X., Qin C., Wang S. and Lic K. 2019. A biomechanical process for cellulose nanofiber production - Towards a greener and energy conservation solution. Carbohydr Polym. 208, 191-199.

16. Qing Y., Sabo R., Zhu J.Y., Agarwal U., Cai Z. and Wu Y. 2013. A comparative study of cellulose nanofibrils disintegrated via multiple processing approaches. Carbohydr Polym. 97, 226-234.

17. Wang X., Zhang K., Zhu M., Hsiao B.S. and Chu B. 2018. Enhanced mechanical performance of self-bundled electrospun fiber yarns via post-treatments. Macromol. Rapid Commun. 29(10),826-831.

18. Phan D.N., Lee H., Huang B., Mukai Y. and Kim I.S. 2019. Fabrication of electrospun chitosan/cellulose nanofibers having adsorption property with enhanced mechanical property. Cellulose 26(3), 1781-1793

19. Phan D.N., Lee H., Huang B., Mukai Y. and Kim I.S. 2016. Fabric Parameter Effect on the Mechanical Properties of Woven Hemp Fabric Reinforced Composites as an Alternative to Wood Products. Adv Res Text Eng 1(1), 1004-1012.

20. Borrell.S., Biswas M.K., Goodwin M., Blomme, G., Schwarzacher T., Wendawek A.M., Berhanu A., Kallow S. 2019. The poorly known Ethiopian crop Enset. Ann. Bot. 123(5), 747-766.

21. Mangesh D., Teli T., Jelalu M. 2017. Chemical, Physical and Thermal Characterization of Ensete ventricosum Plant Fibre. IRJET 04(12),1013-1020.
22. Luo S., Lenon G.B., Gill H., Hung A., Dias D.A 2020. Inhibitory effect of a weight-loss Chinese herbal formula RCM-107 on pancreatic $\alpha$ amylase activity. Enzym. silico approaches 15(4),0231815.

23. Nohwar N. 2017. Production of Cellulose Nano fibers using a Novel Substrate. Eur. J. Biomed. Pharm. Sci. 4(2), 270-276.

24. Alhayat G. T. , Recep E. Yakup A. 2019. Investigation and Characterization of Fine Fiber from Enset Plant for Biodegradable Composites. 17th National 3rd International the Recent Progress Symposium on Textile Technology and Chemistry, 356-360, Doi: , ISBNNO: 978-605-01-1312-9.

25. Poddar P. K. 2015. Synthesis of Nano cellulose from Rubber wood Fibers via Ultra sonication Combined With Enzymatic and Chemical Pretreatments. Asian J. Appl. Sci. 03(05), 520-527.

26. Wang Z.W., Zhu M.Q., Li M.F., Wei Q. and Sun R.C. 2019. Effects of hydrothermal treatment on enhancing enzymatic hydrolysis of rapeseed straw. Renew. Energy 134, 446-452.

27. Teli M.D. and Terega J.M. 2019. Effects of alkalization on the properties of Ensete ventricosum plant fibre. J. Text. Inst.110(4), 496-507.

28. Krishnan A. 2015. Sisal Nano fibril reinforced polypropylene/polystyrene blends: Morphology, mechanical, dynamic mechanical and water transmission studies. Ind. Crops Prod. 71,173-184.

29. Özgenç Ö., Durmaz S., Boyaci I.H. and Eksi K. H. 2017. Determination of chemical changes in heat-treated wood using ATRFTIR and FT Raman spectrometry. Spectrochimica Acta Part A. Mol. Biomol. Spectrosc. 171, 395-400.

30. Meija F. A. 2019. Chemical Alterations of Hardwood Veneers Due to Thermal Treatment. In Proceedings of the 12th International Scientific and Practical Conference, 163.

31. Zhang X., Yang H., Liu M., Chen Y., Xin S. 2020. Vapor-solid interaction among cellulose, hemicellulose and lignin. Fuel 263, 116681.

32. Yan Q. and Cai Z. 2020. Effect of Solvents on Fe-Lignin Precursors for Production Graphene-Based Nanostructures. Molecules 25( 9), 2167.

33. Sarkar P.C., Sahu P.K. , Binsi N N. 2018. Studies on physicochemical and functional properties of some natural Indian Gums. Agric. Res. Commun. Cent. 37(2), 126-131.

34. Mewoli A.E., Segovia C., Ebanda F.B., Ateba A., Noah P.M.A. 2020. Physical-Chemical and Mechanical Characterization of the Bast Fibers of Triumfetta cordifolia A. Rich. from the Equatorial Region of Cameroon. J. Miner. Mater. Charact. Eng. 8(04), 163.

35. Senneca O., Cerciello F., Russo C., Wütscher A. 2020. Thermal treatment of lignin, cellulose and hemicellulose in nitrogen and carbon dioxide. Fuel 271,117656.

36. Abu-Danso E, Srivastava V, Sillanpää M, Bhatnagar A. 2017. Pretreatment assisted synthesis and characterization of cellulose nanocrystals and cellulose nanofibers from absorbent cotton. Int. J. Biol. Macromol. 102, 248-57. 